\title{
DISCRETE EVENT SIMULATION FOR INTEGRATED DESIGN IN THE PRODUCTION AND COMMISSIONING OF MANUFACTURING SYSTEMS
}

\author{
Leonardo das Dores Cardoso \\ Instituto Federal Fluminense \\ 273 Dr. Siqueira St, Pq. Dom Bosco \\ Campos dos Goytacazes, RJ 28030, BRAZIL
}

\author{
João José de Assis Rangel \\ Universidade Candido Mendes \\ 100 Anita Peçanha St, Pq São Caetano \\ Campos dos Goytacazes, RJ 28030, BRAZIL
}

\author{
Patrick Junior Teixeira Bastos \\ Instituto Federal Fluminense \\ 273 Dr. Siqueira St, Pq. Dom Bosco \\ Campos dos Goytacazes, RJ, 28030, BRAZIL
}

\begin{abstract}
This paper presents a hybrid environment for testing and training in control systems in manufacturing. The hybrid environment uses a Discrete Event Simulation (DES) model integrated to didactic stations of manufacturing processes used in the training of students. The control logic of the automated system can operate in real-time and integrate to the process, both in the simulation model as in the manufacturing real system. During the testing, it was clear for the control system, and also for the student, the part of the process represented by the simulation model and the real part of the system. The proposed hybrid approach allowed, somehow, expanding the use of the systems simulated in the training of students in control logic. Several simulation models could be developed and engaged to manufacturing stations, in order to provide to the student more alternatives of tests at the training environment.
\end{abstract}

\section{INTRODUCTION}

Testing and adjustments in a system of manufacturing facilities control of industrial processes usually consume long periods of time and may subject the equipment to operational risks. For control systems of continuous processes, it is possible, in some cases, to use signal generators to test the behavior and the dynamics of the process. On the other hand, in manufacturing system, this task does not involve testing only physical connections of the components and evaluating the signals. In these systems, it is necessary to assess the behavior of the system(s) to a variety of situations, hindering, thus, the accomplishment of testing only with the simulation of input signals by a conventional signal generator. In addition, waiting for the conclusion of the new system to, then, run the tests, can be a lengthy path and generate high costs and risks. However, an alternative that has been commonly employed is the use of Discrete Event Simulation (DES), both during the design phase of the production line, as for the commissioning of their systems of control and monitoring of these lines.

By the middle of the last decade, authors, such as Smith et al. (1994), Wysk et al. (1995), Davis et al. (1996), Dougall (1998) and Auinger et al. (1999), proposed mechanisms for the integration of Discrete Event Simulation (DES) models with control systems. Hibino et al. (2006), Pîrvu et al. (2010), Chiou et al. (2011), Han et al. (2011), Koo et al. (2011) and Ko et al. (2013) used the DES for testing control systems. 
More recently, authors, such as McGregor (2002), Harrison and Tilbury (2008), and suggested the creation of hybrid environments of simulation and real systems for testing in control systems. These hybrid environments may be presented as a viable alternative since they are constructed from the simulation model of the most critical part of the system under consideration. That is, once constructed the simulation model developed to analyze part of the process of interest, it can be integrated with the rest of the real process, where the control system works throughout the system for testing and potentially operation control.

Rangel et al. (2012) also presented a training environment for the study of systems logic of automatic control of industrial processes, using a DES model. They proposed the application of the development environment using Arena simulation models to be employed in the construction of a didactic simulator for use in the teaching of programming of programmable logic controllers (PLC). The results demonstrated that the approach was feasible and it makes possible the development of several analyses in the control system with a same simulation model.

Given this context, this paper presents a proposal of a hybrid environment for testing and training control systems in manufacturing. The hybrid environment uses a DES model integrated with didactic stations of manufacturing processes used in training of students. The control logic of the automated system can operate in the process in real time and in an integrated way, both in the simulation model as in the manufacturing real system. During the testing, it was transparent for the control system, and also for the student, the part of the process represented by the simulation model and the real part of the system.

\section{DESCRIPTION OF THE TESTING SYSTEM}

The hybrid environment for testing and training control system in manufacturing consists of four didactic Stations and also the simulation model. Figure 1 shows the set of Stations and the simulation model, at the background, on the monitor of $42 \mathrm{in}$.

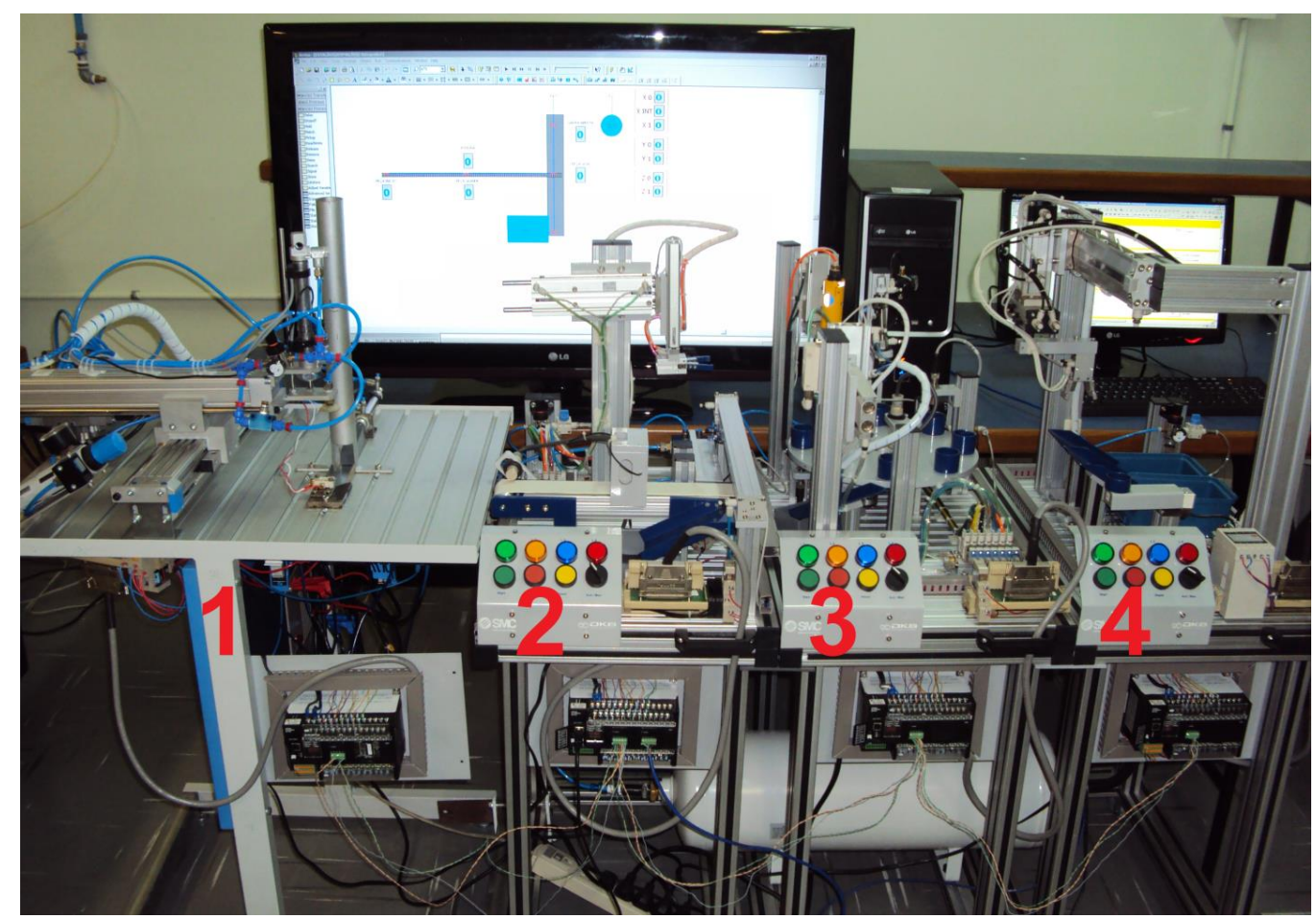

Figure 1: Didactic Stations of manufacturing (Station 1: Feeder; Station 2: Separator of Parts; Station 3: Separator with Processor; and Station 4: Storage) and simulation model (background). 


\section{Cardoso, Rangel, and Bastos}

Parts with different characteristics can be supplied to the Stations. There are five parts of the following types: (1) perforated large metallic; (2) large metallic; (3) large plastic; (4) small metallic; and (5) small plastic. Parts of type 2, 4 and 5 are considered defective and must be discarded during the process. Parts of type 1 go through a polishing operation at Station 2 and are stored in Station 3. Part of type 3 is directly conducted to Station 3 . Figure 2 shows the various parts used in the process.

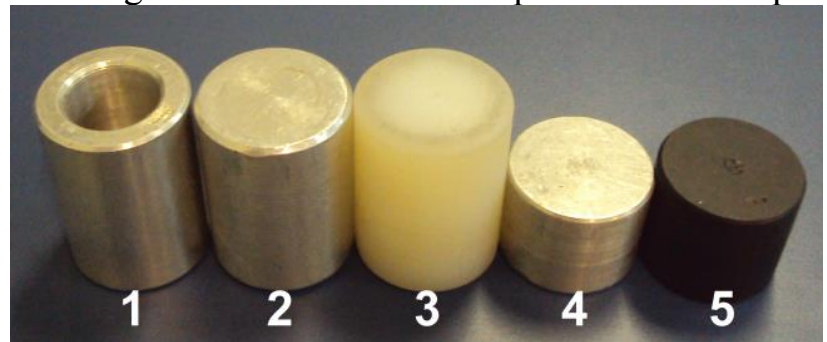

Figure 2: Parts used in the process (1: perforated large metallic; 2: large metallic; 3: large plastic; 4: small metallic; and 5: small plastic).

Figure 3 shows the Station 1. This Station is responsible for moving the parts stored in the feeder (Figure 1) and sending to the Station 2.

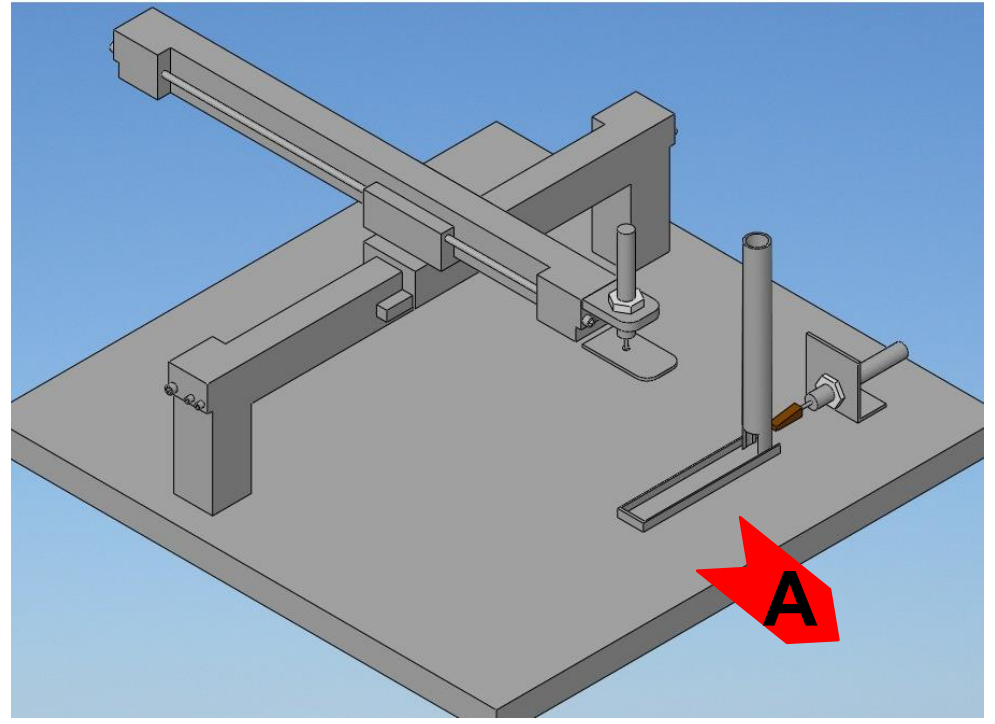

Figure 3: Schematic drawing of the Station 1 (A: delivery of parts to Station 2).

The simulation model was developed to operate in the place of the Station 2 (Separator). This Station serves to discard parts provided by the Station 1 with dimensions out of specification. They are positioned at the beginning of the conveyor and conducted to another one. From there, those parts can go to the next process or be discarded if they do not have the correct dimensions. Figure 4 shows a schematic drawing to describe the cited Station.

The Station 3 (Figure 1: Separator with Processor) performs several operations, among them, the polishing of perforated metallic parts and the discard of the ones without hole. It also sends the plastic parts for the Station 4 . Then, they are moved through a rotary table, having cavities, where are lodged. Figure 5 shows a schematic drawing to describe Station 3. 


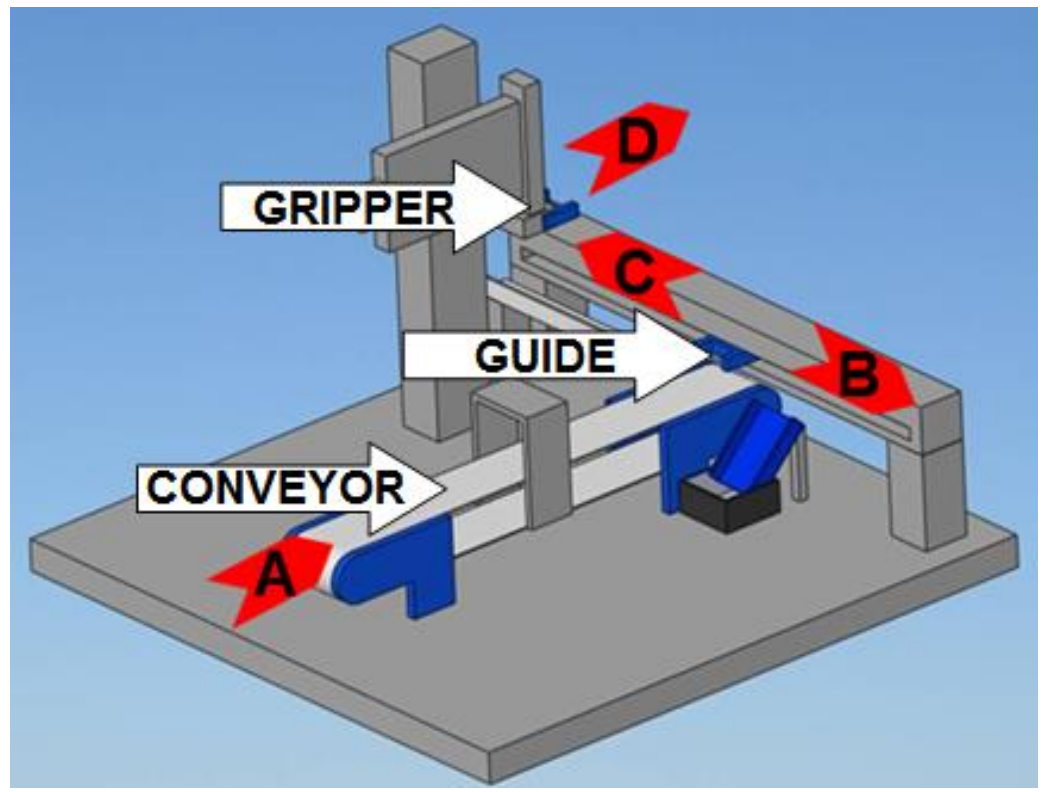

Figure 4: Schematic drawing of the Station 2 (A: parts entry; B: parts discarding; C: parts to be processed; D: delivery of parts to Station 3).

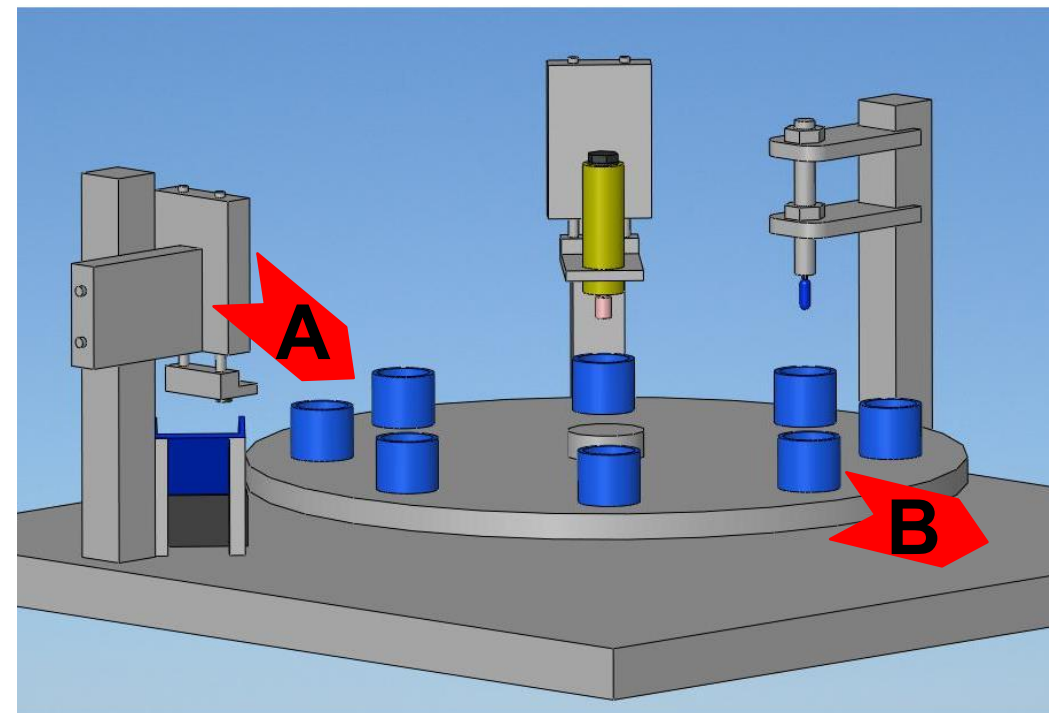

Figure 5: Schematic drawing of the Station 3 (A: parts entrance; B: delivery of parts to Station 4).

\section{SIMULATION MODEL}

The methodology by Banks (2009) was followed to prepare this simulation project, according to the next steps: Formulation and analysis of the hypothetical problem; construction of the conceptual model; construction of the simulation model; verification and validation; and experimentation.

The conceptual model to carry out computer simulations was translated into software Arena (Kelton, Sadowski, and Sturrock 2009). It was used, in addition, the methodology proposed by Sargent (2011) for verification and validation of the model. It is worth mentioning that the computational model was constructed after the conceptual model was ready, completely verified and validated. Figure 6 shows the animation of the simulation model of the Station 2. 


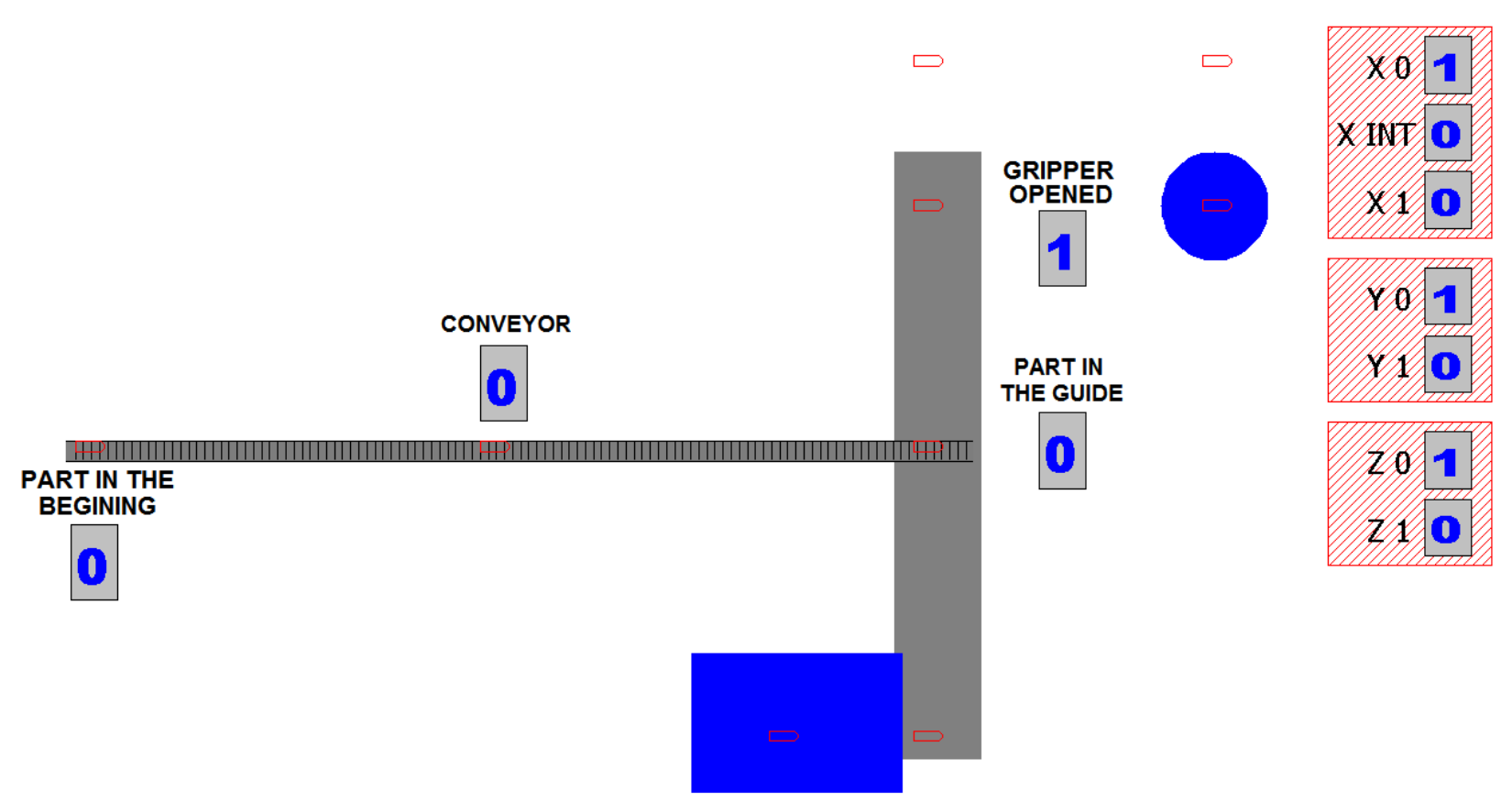

Figure 6: Simulation model of the Station 2.

Simulation model allowed representing the movements carried out with the parts without the use of the real system. The animation developed for the Station presents status indicators of the sensors and the movement of the parts through the process.

After the construction of the simulation model and the control logic in the PLC, it was necessary to establish the communication between the simulation model and the PLC, and, thus, the execution of the experiments.

\section{TESTING AND RESULTS ANALYSIS}

To test the hybrid environment developed, composed by the simulation model and the control system, three logical errors, typically found in industrial manufacturing facilities, were performed in the system. The first mistake was inserted at Station 1. The second was caused in the interaction between Stations 1 and 2. And the last one, similar to the second, was set in the interaction between the Stations 2 and 3.

For connection among the Stations, the communication system, typically used in industrial systems, was employed, that is, a logical signal operated among controllers. Thus, in the case of the tests performed, a signal from the Station 1 to the simulation model was generated. That signal, then, initiated, virtually, the operation of the Station 2. In this way, the interaction of the Station 1 and Station 2 could be analyzed.

The use of the simulation model integrated to the control system allowed evaluating a typical and undesired situation that can occur in automated systems, due to the interference caused by simultaneous movements among stations. In the case of the proposed environment, this interference occurred only virtually. Thus, the operations could be tested without any physical contact and, consequently, without the risk of equipment damage.

\subsection{Preliminary Tests (Virtual Commissioning)}

It was not used all the system during the preliminary tests. Only the simulated Station integrated to the control system was used, thus, conducting the commissioning hardware in the loop. However, this testing 


\section{Cardoso, Rangel, and Bastos}

did not consider the interaction among stations, which is part of the operation that offered the most potential risk to the equipment.

Among the three (3) errors inserted in the logic, one was detected while performing the commissioning hardware in the loop, that is, an individual error of the Station 1. This error caused the unexpected activation of the displacer guide of parts while the conveyor was still moving, as illustrated in Figure 7. This error could damage both the mechanism of the conveyor as the guide. As expected, these tests detected only local errors, showing the limitation of the conventional hardware in the loop in relation to errors in the interface.

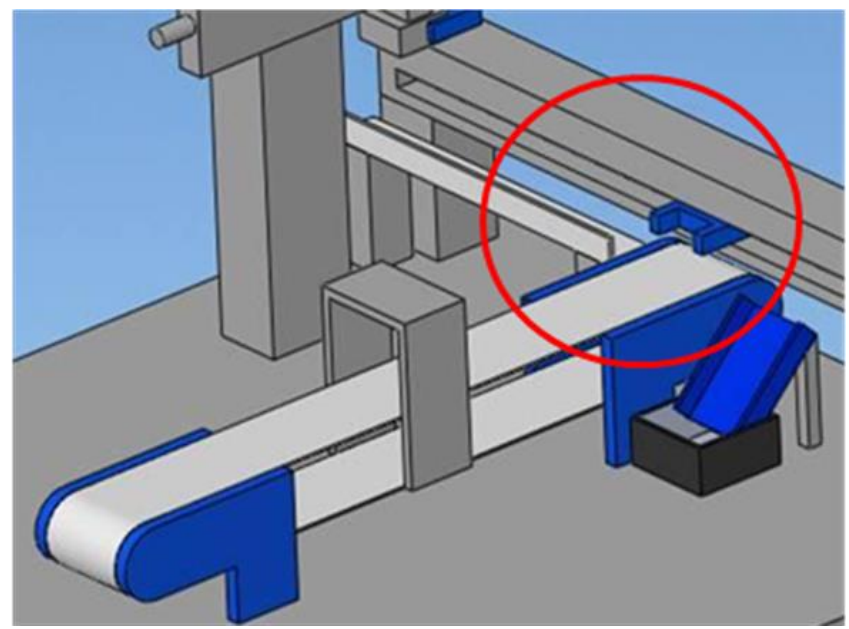

Figure 7: Individual error at the Station 1.

\subsection{Tests using the hybrid commissioning}

In the hybrid commissioning, the model was integrated to the real Stations for testing, enabling the analysis of the interaction among the Stations. During this testing, at the end of the operation, the Station 1 generated a signal to the Station 2, allowing the start of the action. This operation was carried out without physical interaction, avoiding the risk of damage, due to failures in the transition. As the Station 2 was with no power supply, even if there would be an error in logic and the unexpected concurrence of movement of the actuators, it did not compromise the equipment.

At this stage, two (2) logic errors were detected. In the first, the conveyor of the Station 2 was activated while the Station 1 moved to put the part on that conveyor. This error would cause damage to both the mechanism of the conveyor and the actuator responsible for depositing the parts. Figure 8 illustrates the detected error. As, at the time of testing, the Station 2 was maintained without power supply, the error did not cause damage to the equipment.
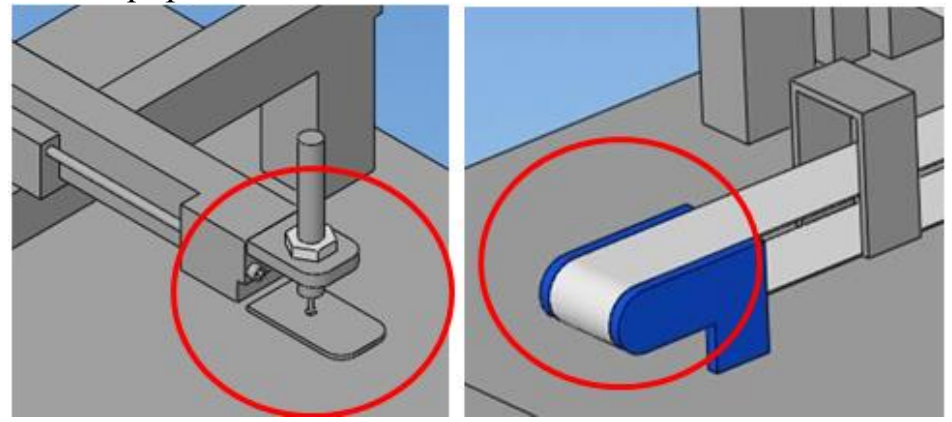

Figure 8: Interaction error Stations 1 and 2. 
The other mistake was found during the interaction between the Stations 2 and 3. In this, the rotary table of the Station 3 was activated while the Station 2 deposited the part as shown in Figure 9. Such a failure could cause serious damage to the mechanism of both Stations if not discovered during the commissioning stage.
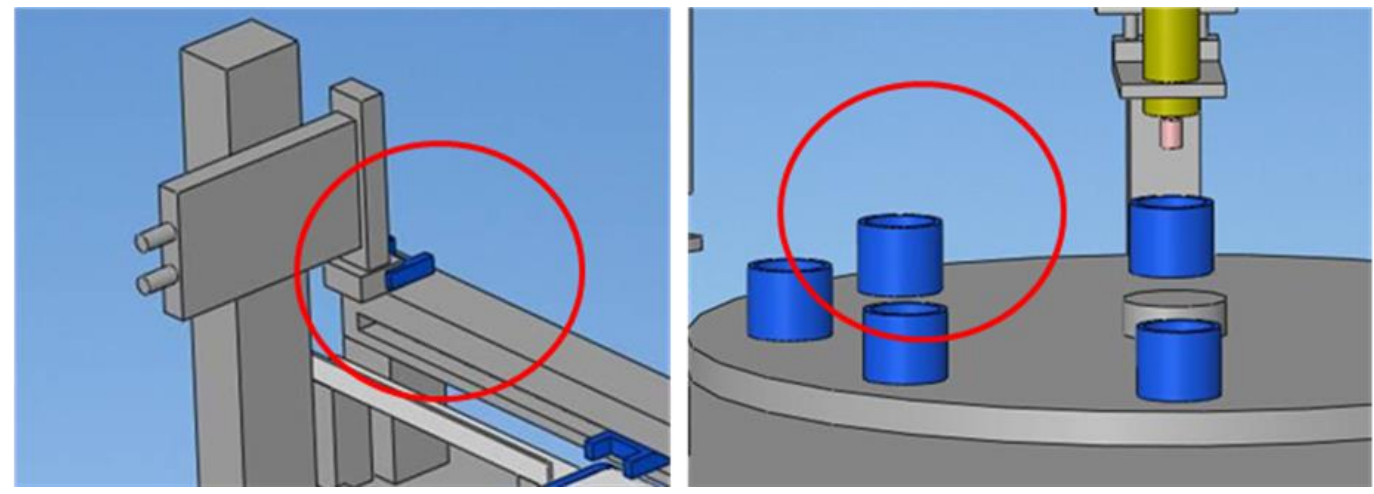

Figure 9: Interaction error at the Stations 2 and 3.

Table 1 presents a summary of the testing performed, and the respective errors observed in the operations. The individual error of the Station 2 was detected and corrected during the performance of the virtual commissioning. Thus, it could not be visualized during the hybrid commissioning.

Table 1: Detected errors.

\begin{tabular}{|c|c|c|c|}
\hline Testing\Error & $\begin{array}{c}\text { Individual } \\
\text { Error Station 2 }\end{array}$ & $\begin{array}{c}\text { Interaction error } \\
\text { Stations 1 and 2 }\end{array}$ & $\begin{array}{c}\text { Interaction error } \\
\text { Station 2 and 3 }\end{array}$ \\
\hline $\begin{array}{c}\text { Virtual } \\
\text { Commissioning }\end{array}$ & detected & undetected & undetected \\
\hline $\begin{array}{c}\text { Hybrid } \\
\text { commissioning }\end{array}$ & - & detected & detected \\
\hline
\end{tabular}

After the hybrid commissioning of the manufacturing facilities, physical tests were performed to verify whether the control logic developed, using the process simulated, would control the physical manufacturing facilities. In these tests, all the Stations were used. During these testing, the power supply of all the Stations was maintained, representing the stage called assisted operation. The manufacturing facilities behaved as expected, proving the efficiency of the hybrid commissioning.

\section{CONCLUDING REMARKS}

The hybrid environment, consisting of the simulation model and the didactic system of automated manufacturing with network communications, was developed, and it was demonstrated that the interface worked properly. The real-time communication between the controller and the simulation model was achieved using this process, and the simulation model behaved similarly to the real system.

The proposed approach demonstrated the possibility of using the hybrid environment to carry out repairs and testing on similar industrial systems. In these cases, a simulation model can be constructed specifically for the part of interest, and be evaluated the operation of a complete process with greater safety.

The DES was presented as being a potential approach to assist the development and testing of control systems. This is considered a complex stage of the project. The use of this approach can make possible the construction of a control system more reliable, with a lower number of errors since various changes 


\section{Cardoso, Rangel, and Bastos}

can be made still in the testing phase. The integration of the control system to the model developed allowed analyzing the behavior of the station individually.

This hybrid approach allowed, in a way, expanding the use of the systems simulated in training of students in control logic. Several simulation models could be developed and engaged to manufacturing stations, in order to provide to the student more alternatives of testing at the training environment.

\section{ACKNOWLEDGMENTS}

The authors would like to thank the National Council of Technological and Scientific Development CNPq and the Foundation for Research Support of Rio de Janeiro - FAPERJ for financial support for this research. They also thank Maria Marta Garcia for the suggestions on the text in English.

\section{REFERENCES}

Auinger, F., M. Vordewinkler, and G. Buchtela. "Interface Drive Domain - Independent modeling architecture for "soft-comissioning and reality in the loop." In Proceedings of the 1999 Winter Simulation Conference, edited by P. A. Farrington, H. B. Nembhard, D. T. Sturrock, and G. W. Evans, 798-805. Piscataway, New Jersey: Institute of Electrical and Electronics Engineers, Inc.

Banks, J., J. S. Carson, B. L. Nelson, and D. M. Nicol. 2009. Discrete-Event System Simulation. 5th ed. Upper Saddle River, New Jersey: Prentice-Hall, Inc.

Chiou, R., Y. Kwon, R. Kizirian, M. Dordai, and B. A. Davis "Modeling and experimental verification of PLC codes in a robotics and mechatronics course". In Proceedindgs of the 2011 118th American Society for Engineering Education. Vancouver, BC - Canada.

Davis, W, J., J. G. Macro, A. L. Brook, M. S. Lee, and G. S. Zhou "Developing a Real-Time Emulation/Simulation Capability for the Control Architecture to the Ramp FMS". In Proceedings of the 1996 Winter Simulation Conference, edited by ed. J. M. Charnes, D. J. Morrice, D. T. Brunner, and J. J. Swain, 171-178. Piscataway, New Jersey: Institute of Electrical and Electronics Engineers, Inc.

Dougall, D. J. 1998. "Applications and Benefits of Real-Time I/O Simulation for PLC and PC Control Systems." ISA Transactions. 36(4)305-311.

Han, K. H.; Choi, S. H.; Park, J. W., and Lee, J. W. 2011. "Rapid Virtual Prototyping and Operational Monitoring of PLC-Based Control System." International Journal of Mathematics and Computers in Simulation. Vol. 5, N. 3, 198-205.

Harrison, W. S., and D. Tilbury "Virtual Fusion: Hybrid Process Simulation and Emulation-in-the-loop". In: Proceedings of the 2008 9th Biennial ASME Conference on Engineering Systems Design and Analysis, Haifa - Israel, 1-10.

Hibino, H., T. Inukai, and Y. Fukuda. 2006 "Efficient manufacturing system implementation based on combination between real and virtual factory." International Journal of Production Research. 44(1819):3897-3915.

Kelton, W. D., R. P. Sadowski, and N. B. Sturrock 2007. Simulation with Arena. 5th ed. New York: Mcgraw-Hill.

Ko, M., S. C. Park, J. Choi, and M. Chang. 2013 "New Modelling Formalism for Control Programs of Flexible Manufacturing Systems. International Journal of Production Research. 51:6:1668-1679.

Koo, L. J., C. M. Park, C. H. Lee, S. C. Park, and G. Wang, 2011 "Simulation Framework for the Verification of PLC Programs in Automobile Industries." International Journal of Production Research. 49(16):4925-4943.

McGregor, I. "The Relationship Between Simulation and Emulation", In Proceedings of the 2002 Winter Simulation Conference, edited by E. Yücesan, C.-H. Chen, J. L. Snowdon, and J. M. Charnes, 16011612. Piscataway, New Jersey: Institute of Electrical and Electronics Engineers, Inc. 
Pîrvu, B., I. Bondrea, C. Simion, and R. Marin. 2008, "Modelling and Control of an Automated Module Using Discrete Event Simulation and Object-Based Modeling." Academic Journal of Manufacturing Engineering. 8(2)63-68.

Rangel, J. J. A., A. A. Souza, P. J. T. Bastos, and R. C. T. Baptista. 2012. "Simulação a Eventos Discretos para Treinamento em Sistemas de Controle. "Revista Pesquisa Operacional para o Desenvolvimento. 4(1)97-111.

Sargent, R. G. 2011. "Verifications and Validation of Simulations Models." In Proceedings of the 2011 Winter Simulation Conference, edited by S. Jain, R. R. Creasey, J. Himmelspach, K. P. White and M. $\mathrm{Fu}, 183-198$. Piscataway, New Jersey: Institute of Electrical and Electronics Engineers, Inc.

Smith, J.S.; R. A. Wysk, D. T. Sturrock, S. E. Ramaswamy, G. D. Smith, and S. B. Joshi. "Discrete Event Simulation for Shop Floor Control". In Proceedings of the 1994 Winter Simulation Conference, edited by J. D. Tew, S. Manivannan, D. A. Sadowski, and A. F. Seila, 962-969. Piscataway, New Jersey: Institute of Electrical and Electronics Engineers, Inc.

Viswanathan, J., W. S. Harrison, D. M. Tilbury and F. Gu "Using Hybrid Process Simulation to Evaluate Manufacturing System Component Choices: Integrating a virtual robot with the physical system", In Proceedings of the 2011 Winter Simulation Conference, edited by S. Jain, R. R. Creasey, J. Himmelspach, K. P. White and M. Fu, 2827-2838. Piscataway, New Jersey: Institute of Electrical and Electronics Engineers, Inc.

Wysk, R.A., B. A. Peters, and J. S. Smith 1995. "A Formal Process Planning Schema for Shop Floor Control." Engineering Design and Automation Journal 1(1)3-19.

\section{AUTHOR BIOGRAPHIES}

LEONARDO DAS DORES CARDOSO is an Industrial Engineering degree from Candido Mendes University (UCAM-Campos) in Campos dos Goytacazes, RJ - Brazil, and a Control and Automation Engineering degree from Federal Fluminense Institute (IFF-Campos) in Campos dos Goytacazes, RJ - Brazil. He is currently a teacher at Federal Fluminense Institute (IFF) and MSc student in Industrial Engineering at UCAM-Campos. His e-mail is leonardo.cardoso@iff.edu.br.

JOÃO JOSÉ DE ASSIS RANGEL is a professor at Federal Fluminense Institute (IFF) and Candido Mendes University (UCAM-Campos) in Campos dos Goytacazes, RJ - Brazil. He received a doctoral degree in Materials Engineering at UENF in 1998. His research interests include Simulation on Logistics and Manufacturing, Simulation on Super Hard Materials Process and Simulation Education. His e-mail address is joao@ucam-campos.br.

PATRICK JUNIOR TEIXEIRA BASTOS is a Control and Automation Engineering degree from Federal Fluminense Institute (IFF) in Campos dos Goytacazes, RJ - Brazil. His e-mail is patrickbastos01@gmail.com. 